\title{
Snba t
}

3two Recenfionen betr ben urfprung ber Ëpradie S. I.

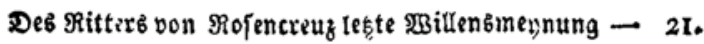
Fhilologifde (sinfálle und 3̧weifel úber eine ata:

bemifhe 9 reibfarrift . . . . - 37.

Gelbftgeíprád) cineb Zutors . • • . - 73 .

Benlage zun Dentrúrbigfeiten bę fel. હofrates - 97.

Reue zpologie bes Budftaben $\mathfrak{5}$. . . - - 115 .

Lettre perdue d'un Sauvage du Nord . - I49.

In bie Şere zu Rabmonbor . . . . - - 169.

Chrift. Zacch. Telonarchae Prolegomena úbær

bie neuefte 2ualegung ze. . . . . - $18 \mathrm{I}$.

Le Kermès du Nord . . . . . - 201 .

Drandierley und (Etras von einem Recenjenten

trauriger Beftalt . . . . . - $21 \mathrm{I}$.

פerfud einer बibylle úber bie EGe . . - 223.

ફ̧ierophantifje 2 Briefe . . . . . -233 .

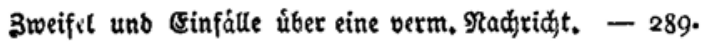

Sileine 2uffáąe von 1770 bid 1776. • . - 339. 


\section{$\mathfrak{S} \mathfrak{a} \mathfrak{m} \mathfrak{a} \mathfrak{n} \mathfrak{n}^{\prime} \mathfrak{z}$ \\ (5) $\mathfrak{x} \mathfrak{i} \mathfrak{f} \mathfrak{t} \mathfrak{e}$}

S.era

oon

Fricorid

$\mathfrak{N}$ ierter $\mathfrak{T} \mathfrak{h}$ e $\mathfrak{i l}$.

Bertit ,

be y. \&. Reimer I823. 
